Article

\title{
Rippled $\beta$-Sheet Formation by an Amyloid- $\beta$ Fragment Indicates Expanded Scope of Sequence Space for Enantiomeric $\beta$-Sheet Peptide Coassembly
}

\author{
Jennifer M. Urban ${ }^{1} \mathbb{D}$, Janson Ho ${ }^{1} \mathbb{D}$, Gavin Piester ${ }^{1}$, Riqiang Fu ${ }^{2} \mathbb{D}$ and Bradley L. Nilsson ${ }^{1, * \mathbb{C}}$ \\ 1 Department of Chemistry, University of Rochester, Rochester, NY 14627-0216, USA; \\ jurban4@ur.rochester.edu (J.M.U.); janson.ho1@gmail.com (J.H.); gpiester@u.rochester.edu (G.P.) \\ 2 The National High Magnetic Field Laboratory, Florida State University, 1800 East Paul Dirac Drive, \\ Tallahassee, FL 32310, USA; rfu@magnet.fsu.edu \\ * Correspondence: bradley.nilsson@rochester.edu; Tel.: +1-585-276-3053
}

Received: 15 April 2019; Accepted: 22 May 2019; Published: 23 May 2019

\begin{abstract}
In 1953, Pauling and Corey predicted that enantiomeric $\beta$-sheet peptides would coassemble into so-called "rippled" $\beta$-sheets, in which the $\beta$-sheets would consist of alternating $\mathrm{L}$ - and D-peptides. To date, this phenomenon has been investigated primarily with amphipathic peptide sequences composed of alternating hydrophilic and hydrophobic amino acid residues. Here, we show that enantiomers of a fragment of the amyloid- $\beta(\mathrm{A} \beta)$ peptide that does not follow this sequence pattern, amyloid- $\beta$ (16-22), readily coassembles into rippled $\beta$-sheets. Equimolar mixtures of enantiomeric amyloid- $\beta$ (16-22) peptides assemble into supramolecular structures that exhibit distinct morphologies from those observed by self-assembly of the single enantiomer pleated $\beta$-sheet fibrils. Formation of rippled $\beta$-sheets composed of alternating L- and D-amyloid- $\beta$ (16-22) is confirmed by isotope-edited infrared spectroscopy and solid-state NMR spectroscopy. Sedimentation analysis reveals that rippled $\beta$-sheet formation by $\mathrm{L}$ - and $\mathrm{D}$-amyloid- $\beta$ (16-22) is energetically favorable relative to self-assembly into corresponding pleated $\beta$-sheets. This work illustrates that coassembly of enantiomeric $\beta$-sheet peptides into rippled $\beta$-sheets is not limited to peptides with alternating hydrophobic/hydrophilic sequence patterns, but that a broader range of sequence space is available for the design and preparation of rippled $\beta$-sheet materials.
\end{abstract}

Keywords: peptide coassembly; rippled $\beta$-sheets; amphipathic peptides; enantiomeric coassembly

\section{Introduction}

Cross- $\beta$ amyloid fibrils are $\beta$-sheet rich supramolecular assemblies formed by a wide variety of peptides and proteins. The unregulated self-assembly of peptides and proteins into amyloid aggregates is characteristic of protein misfolding pathologies that notably include Alzheimer's disease, Parkinson's disease, and prion encephalopathies [1-4]. Amyloid fibrils have also evolved as regulated functional materials in biological systems [5-9]. These materials have inspired extensive efforts in the development of novel supramolecular biomaterials composed of peptides that self-assemble into amyloid or amyloid-like architectures with engineered emergent properties [10-12].

Rippled $\beta$-sheets are an emerging class of amyloid-inspired material. In 1953, Pauling and Corey predicted that enantiomeric $\beta$-sheet peptides would selectively coassemble into so-called "rippled $\beta$-sheets" composed of alternating L- and D-peptides [13]. These two-component assemblies were expected to adopt a rippled appearance, as opposed to the pleated structure of single-enantiomer $\beta$-sheets. One of the earliest experimental examples of enantiomeric peptide coassembly was of mixtures of poly(L-lysine) and poly(D-lysine), though the resulting assemblies were only recently 
proven to be composed of racemic $\beta$-sheets [14,15]. Similarly, mixtures of poly(L-glutamic acid) and poly(D-glutamic acid) have been found to coassemble into amyloid-like fibrils, albeit slowly and with many defects [16]. Enantiomeric amphipathic peptides with alternating polar/nonpolar amino acid sequence patterns have been recently shown to coassemble into rippled $\beta$-sheet materials [17-20]. For example, we discovered that mixtures of $\mathrm{L}-$ and $\mathrm{D}-\mathrm{Ac}-(\mathrm{FKFE})_{2}-\mathrm{NH}_{2}$ peptides (Figure 1A), which readily self-assemble into bilayer nanoribbon fibrils, preferentially coassemble into rippled $\beta$-sheets in which the $L$ - and D-peptides alternate with high fidelity. The coassembled rippled $\beta$-sheets were found to be energetically more stable than the corresponding one-component pleated $\beta$-sheet assemblies $[17,18]$. Schneider and coworkers also found that enantiomers of the MAX1 peptide (Figure 1B), a $\beta$-hairpin peptide that self-assembles into $\beta$-sheet bilayer fibrils that form hydrogel networks, also coassemble into rippled $\beta$-sheet fibrils $[19,20]$. Furthermore, hydrogels formed from coassembled $\mathrm{L}$ - and $\mathrm{D}-\mathrm{Ac}-(\mathrm{FKFE})_{2}-\mathrm{NH}_{2}$ and $\mathrm{L}-$ and $\mathrm{D}-\mathrm{MAX} 1$ were found to be mechanically stronger than those formed from a single enantiomer $[17,20]$. Recent structural analysis of the MAX1 rippled $\beta$-sheets shows that the enhanced viscoelasticity of the rippled $\beta$-sheet relative to the pleated $\beta$-sheet hydrogel networks is due to the distinctive rippled structure of the two-component fibrils [19].
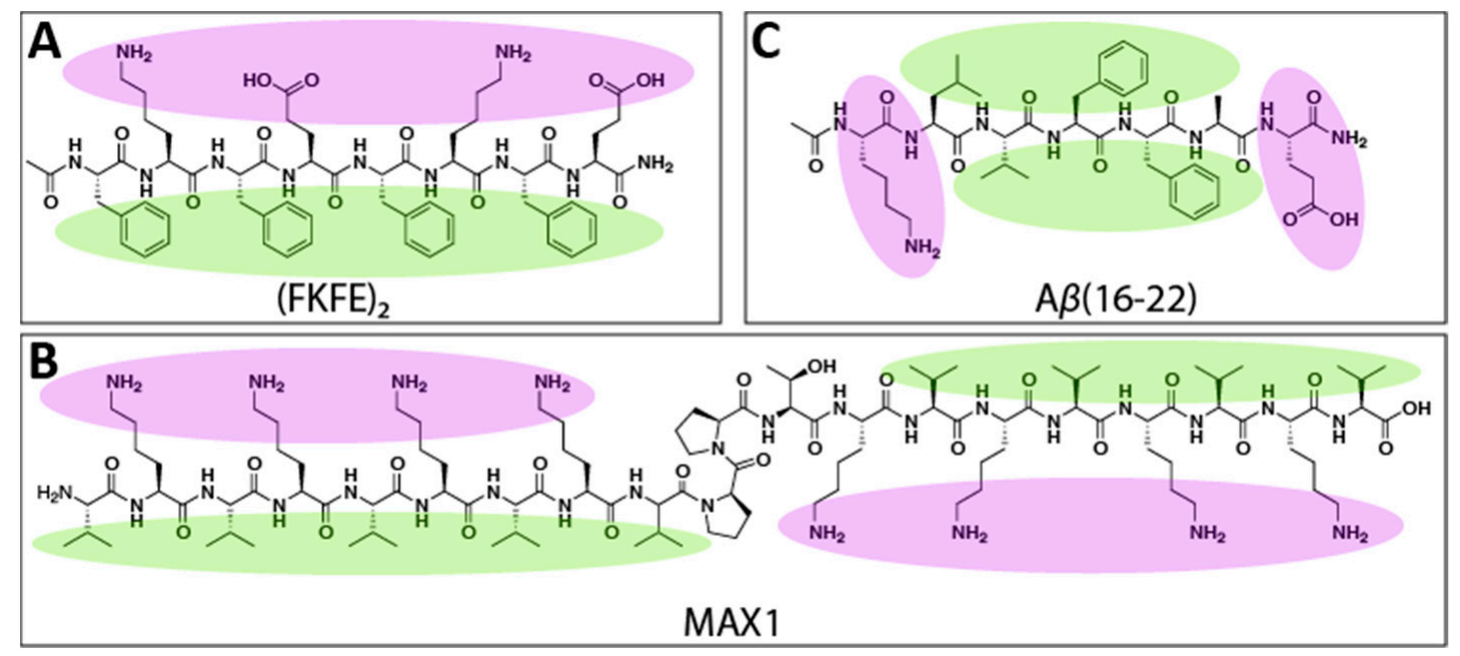

Figure 1. Structures of (A). Ac-(FKFE) ${ }_{2}-\mathrm{NH}_{2}$, (B). MAX1, and (C). A $\beta(16-22)$ with the nonpolar side chains highlighted in green and polar side chains in purple.

These rippled $\beta$-sheets identified by Schneider and Nilsson are formed by similar peptides with alternating polar and nonpolar amino acid sequences. This raises the question as to whether the coassembly of enantiomeric peptides into rippled $\beta$-sheets is unique to this class of self-assembling peptide or if rippled $\beta$-sheets can be formed generally by any self-assembling $\beta$-strand peptide regardless of sequence pattern. In this study, we investigate whether enantiomeric peptide coassembly into rippled $\beta$-sheets can be extended to a peptide that does not display alternating polar/nonpolar sidechains by studying the coassembly propensity of enantiomers of a well-studied self-assembling fragment of the Alzheimer's disease amyloid- $\beta$ peptide, $\mathrm{A} \beta(16-22)$ (Ac-KLVFFAE- $\mathrm{NH}_{2}$, Figure 1C). Comprising the hydrophobic core of amyloid- $\beta$, the residues 16-22 are believed to be critical in the assembly mechanism of the full-length peptide. The 16-22 residue fragment readily self-assembles into amyloid-like fibrils reminiscent of those formed by the parent peptide, and as such, A $\beta(16-22)$ has served as a model peptide in many investigations into amyloid peptide self-assembly [21-27]. The $\mathrm{A} \beta(16-22)$ peptide lacks the alternating polar/nonpolar amino acid sequence pattern common to Ac-(FKFE) $)_{2}-\mathrm{NH}_{2}$ and MAX1. Instead, the polar residues of $\mathrm{A} \beta(16-22)$ are isolated at the $\mathrm{N}$ - and $C$-termini, with the intervening amino acids comprising a nonpolar core (as shown in Figure 1C). We anticipated that an interrogation of the coassembly propensity of the $\mathrm{L}$ - and D-enantiomers of 
$\mathrm{A} \beta(16-22)$ would provide insight into the possibility that rippled $\beta$-sheet assembly may be a general property of all $\beta$-sheet peptides, as predicted by Pauling and Corey.

\section{Results and Discussion}

The self-assembly of $\mathrm{L}$ - and $\mathrm{D}-\mathrm{Ac}-\mathrm{KLVFFAE-} \mathrm{NH}_{2}$ peptides was compared to the assembly properties of an equimolar mixture of the enantiomers. The peptides were prepared via standard Fmoc solid phase peptide synthesis, purified by reverse-phase HPLC, and characterized by MALDI-TOF mass spectrometry (see Materials and Methods section for experimental details and Supplementary Materials for characterization and purity data). Prior to self-assembly, peptides were disaggregated by sequential treatment with trifluoroacetic acid and hexafluoroisopropanol using a modified Wetzel protocol [28]; peptide concentrations were determined by comparison to standard analytical HPLC curves (see Supplementary Materials for details), as described previously for studies with $A \beta(16-22)[22,23]$. Disaggregated, lyophilized peptides were then dissolved in DMSO and diluted into phosphate-buffered saline ( $\mathrm{pH}$ 7.4) to reach total peptide concentrations of $110 \mu \mathrm{M}(55 \mu \mathrm{M}$ of each $\mathrm{L}-$ and D-enantiomer for mixed coassembly studies) (final DMSO concentration was $5 \% v / v$ ). Upon dilution, peptides were incubated at $37^{\circ} \mathrm{C}$ for assembly. Immediately after gentle mixing, visible precipitate was observed in the L/D mixed samples, but not in the single enantiomer self-assembly controls (see Figure 2A), indicating much more rapid assembly in the mixed enantiomer samples consistent with rippled $\beta$-sheet formation.

A

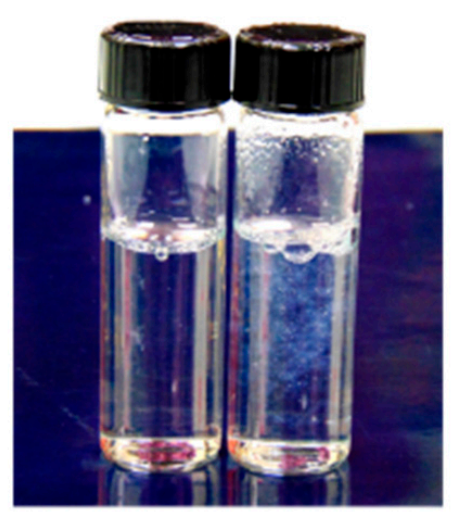

C

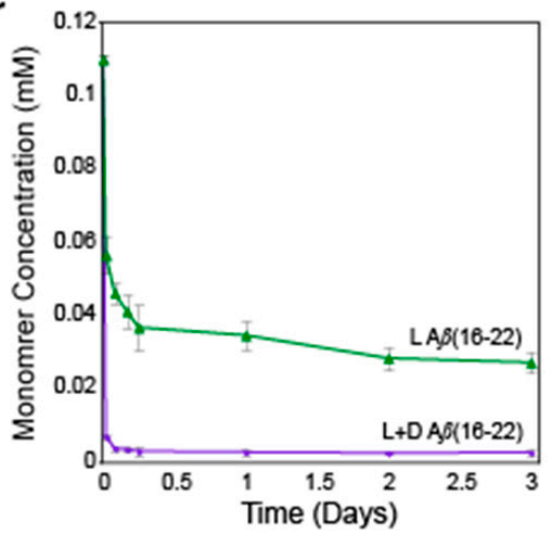

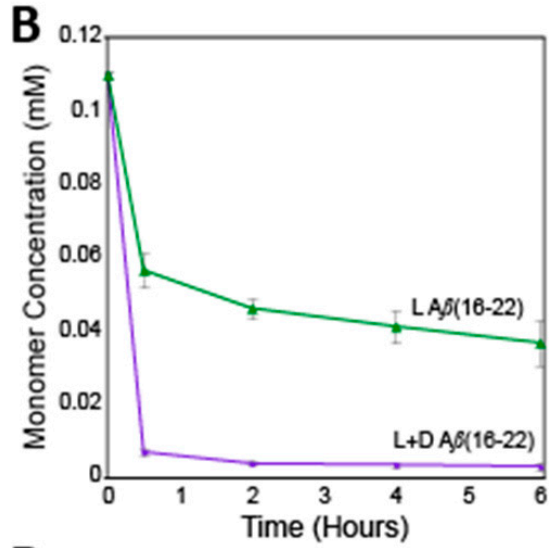

D

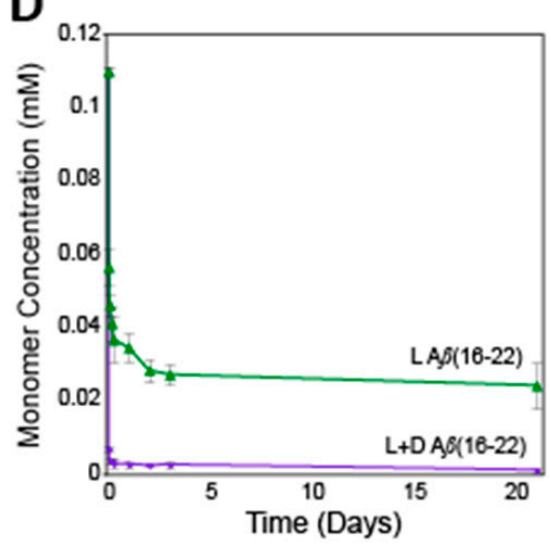

Figure 2. (A). Digital image of L-A $\beta(16-22)$ self-assembly (left) and L/D-A $\beta(16-22)$ coassembly (right) immediately after mixing. (B). Sedimentation data over six hours. (C). Sedimentation data over three days. (D). Sedimentation data over 21 days. 


\subsection{Sedimentation Analysis}

Comparison of self-assembly and coassembly of $A \beta(16-22)$ was conducted by a time-dependent sedimentation analysis. For these studies, we adapted Wetzel's HPLC sedimentation protocol [28] that we have previously used to assess $A \beta(16-22)$ self-assembly [22,23]. Aliquots of self-assembly and coassembly mixtures were removed over time and subjected to ultracentrifugation to remove fibrils and lower order aggregates after which the concentration of unaggregated peptide was quantified. In these analyses, equilibrium between monomer and fibril is eventually reached, with the final monomer concentration, or critical concentration $\left(C_{r}\right)$, providing a quantitative characterization of the dynamic equilibrium between fibrils of length $n$ and monomer with fibrils of length $n+1$. This $C_{r}$ value is inversely related to the association constant for the addition of monomer to fibril, $K_{a}$, as shown in Equation (1). The $K_{a}$ value can be used to determine the relative free energy, $\Delta \mathrm{G}$, for addition of monomer to fibril at equilibrium [28].

$$
C_{r}=\frac{\left[\text { fibril }_{n}\right][\text { monomer }]}{\left[\text { fibril }_{n+1}\right]}=\frac{1}{K_{a}}
$$

Sedimentation analysis revealed distinctive kinetic and thermodynamic properties for the pleated $\beta$-sheet self-assembly of single enantiomers of $A \beta(16-22)$ compared to rippled $\beta$-sheet coassembly of the mixed enantiomers. The $\mathrm{L} / \mathrm{D}-\mathrm{A} \beta(16-22)$ mixture showed a rapid decrease in monomer concentration within 30 min of mixing (Figure 2B-D). After six hours, the coassembly sample had essentially reached equilibrium (Figure 2B). In contrast, the single enantiomer self-assembly samples required over two weeks to reach a constant monomer concentration (Figure 2C,D). The self-assembled single enantiomer $\mathrm{A} \beta(16-22)$ sample had a $C_{r}$ of $24 \pm 6 \mu \mathrm{M}$, corresponding to a $\Delta \mathrm{G}$ value of $-6.6 \pm 0.2 \mathrm{kcal} \mathrm{mol}^{-1}$, consistent with our previously reported data [22,23]. Samples containing 1:1 L:D A $\beta(16-22)$ had a significantly lower $C_{r}$ of $1.1 \pm 0.8 \mu \mathrm{M}$ with a corresponding $\Delta \mathrm{G}$ of $-8.4 \pm 0.4 \mathrm{kcal} \mathrm{mol}^{-1}$. Thus, rippled $\beta$-sheet coassembly has a $\Delta \Delta \mathrm{G}$ of $-1.8 \mathrm{kcal} \mathrm{mol}^{-1}$ relative to pleated $\beta$-sheet self-assembly of the $\mathrm{L}$ - or D-enantiomers alone, revealing a significant enhancement in thermodynamic stability for the coassembled rippled $\beta$-sheet $A \beta(16-22)$ aggregates. This is consistent with the enhanced thermodynamic stability of rippled $\beta$-sheets of the amphipathic Ac-(FKFE) ${ }_{2}-\mathrm{NH}_{2}$ peptide [18]. Note, complementary thioflavin $\mathrm{T}$ (ThT) fluorescence assays were not performed in addition to the sedimentation analysis due to the literature precedent of low binding affinity and low fluorescence response of ThT to A $\beta(16-22)$ aggregates [23,29-32].

\subsection{Transmission and Scanning Electron Microscopy}

The morphology of the self-assembled and coassembled materials was compared by transmission electron microscopy (TEM). As shown in Figure 3A,B, the L- and D-single enantiomer, self-assembled, pleated $\beta$-sheets formed flexible twisted fibrils with widths of $11.8 \pm 0.5 \mathrm{~nm}$, consistent with previous reports [22,23]. However, the mixed L/D aggregates exhibited dramatically different morphologies that were rigid with a semi-crystalline appearance, having widths ranging from $43-593 \mathrm{~nm}$ (Figure 3C). Scanning electron microscopy (SEM) confirmed this unique morphology for the coassembly structures (Figure 3D). While these putative rippled $\beta$-sheet assemblies appear semi-crystalline in microscopic images, they lacked sufficient dimensionality for single crystal X-ray diffraction (see Figure 3D). The morphologies of each sample were very reproducible and did not change over time. Once fibrils form in the L- and D-single enantiomer samples (several days), no changes were seen over 21 days. Immediately after dissolution, the mixed L/D aggregates appear as rigid, semi-crystalline structures with no major changes over 21 days. The distinctive morphology of the $\mathrm{L} / \mathrm{D}$ aggregates of $\mathrm{A} \beta(16-22)$ is consistent with the unique morphologies observed for nanofibrils of mixed enantiomer Ac-(FKFE) $)_{2}-\mathrm{NH}_{2}$ rippled $\beta$-sheets compared to their self-assembled counterparts, providing further evidence that $A \beta(16-22)$ enantiomers also assemble into rippled $\beta$-sheet structures [18]. 

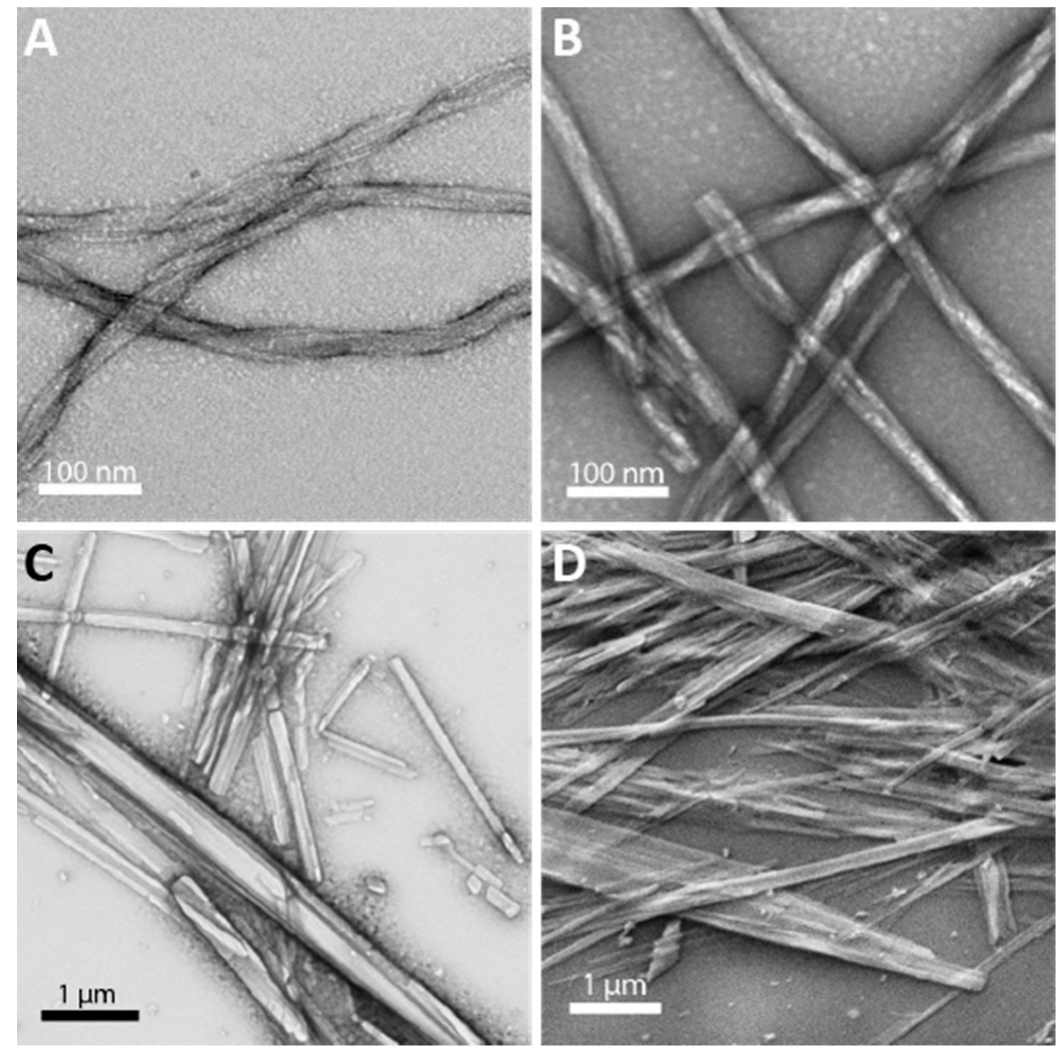

Figure 3. Transmission electron micrographs of assemblies formed by (A). L-A $\beta(16-22)$, (B). D-A $\beta(16-22)$, and (C). L/D-A $\beta(16-22)$. (D). Scanning electron micrograph of assemblies formed by $\mathrm{L} / \mathrm{D}-\mathrm{A} \beta(16-22)$.

\subsection{Isotope Edited Infrared Spectroscopy}

In order to confirm that the $\mathrm{L}$ - and $\mathrm{D}$-enantiomers of $\mathrm{A} \beta(16-22)$ were indeed packing into alternating L/D rippled $\beta$-sheets, we conducted isotope-edited infrared (IE-IR) spectroscopy studies. Antiparallel $\beta$-sheets have characteristic IR amide I stretching frequencies at 1624 and $1690 \mathrm{~cm}^{-1}$, as was seen for the assemblies of $\mathrm{L}-\mathrm{A} \beta(16-22)$, D-A $\beta(16-22)$, and $\mathrm{L} / \mathrm{D}-\mathrm{A} \beta(16-22)$ (Figure $4 \mathrm{~A})$. Isotope edited IR (IE-IR) was used to further our understanding of these assemblies. To this end, we synthesized L-A $\beta(16-22)$ with ${ }^{13} \mathrm{C}$ labels at the carbonyls of L17 and F20. When this labeled peptide self-assembles, these heavier atoms are in close proximity and coupled (see Figure 4B), resulting in the shifting and splitting of the characteristic $\beta$-sheet peak at $1624 \mathrm{~cm}^{-1}$ to $1641 \mathrm{~cm}^{-1}$ and $1598 \mathrm{~cm}^{-1}$ (Figure $4 \mathrm{~A}$, black trace). Next, this labeled L-A $\beta(16-22)$ was mixed with an equimolar amount of unlabeled D-A $\beta(16-22)$. If the enantiomeric strands were self-sorting, we would expect these $1641 \mathrm{~cm}^{-1}$ and $1598 \mathrm{~cm}^{-1}$ signals to be preserved because the cross-strand coupling would not be interrupted. However, we saw instead a shift of these signals to $1638 \mathrm{~cm}^{-1}$ and $1608 \mathrm{~cm}^{-1}$ with a corresponding smaller splitting (Figure 4A, blue trace). This $10 \mathrm{~cm}^{-1}$ shift in the higher energy peak from $1598 \mathrm{~cm}^{-1}$ to $1608 \mathrm{~cm}^{-1}$ indicates that the unlabeled $\mathrm{D}-\mathrm{A} \beta(16-22)$ is in a cross-strand packing arrangement with the labeled $\mathrm{L}-\mathrm{A} \beta(16-22)$ peptide such that it interrupts the coupling between the labeled carbonyls. Similar shifts of 9 to $10 \mathrm{~cm}^{-1}$ in other self-assembled systems clearly indicate changes in coupling state, thus these data indicate that enantiomers of $A \beta(16-22)$ also coassemble into Pauling and Corey's rippled $\beta$-sheets with alternating L- and D-strands as modeled in Figure 4C [18,19]. 


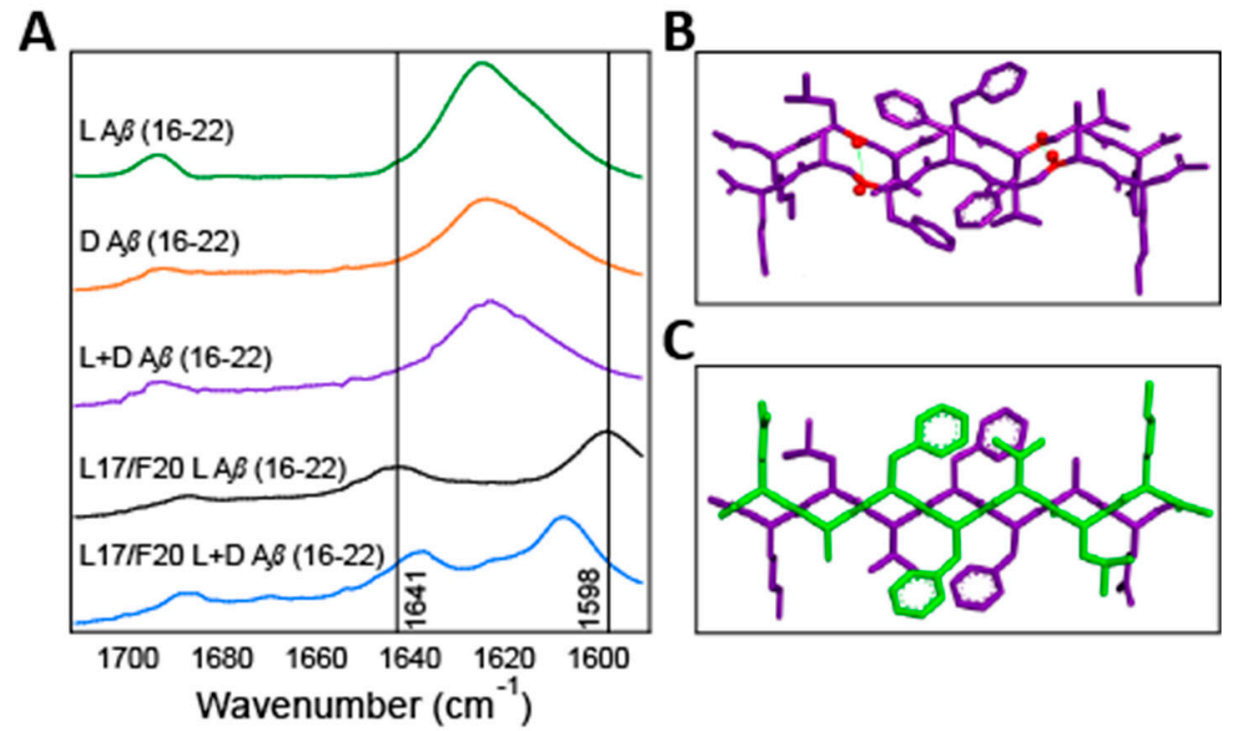

Figure 4. (A). Fourier Transform Infrared Spectroscopy (FTIR) overlays of self-assembled L- and D-A $\beta(16-22)$, coassembled L/D-A $\beta(16-22),{ }^{13}$ C labeled L-A $\beta(16-22)$, and coassembled ${ }^{13} \mathrm{C}$ L-/ unlabeled D-A $\beta(16-22)$. (B). A structural model for putative pleated $\beta$-sheets of self-assembled L-A $\beta(16-22)$ with ${ }^{13} \mathrm{C}$ labeled positions highlighted in red. (C). A proposed structural model L/D-A $\beta(16-22)$ coassembled rippled $\beta$-sheets.

\subsection{Solid-State Nuclear Magnetic Resonance Spectroscopy}

Finally, we used solid-state nuclear magnetic resonance (ssNMR) spectroscopy to confirm formation of rippled $\beta$-sheets and to validate our models for the $\beta$-sheet packing structure for both pleated and rippled $\beta$-sheet assemblies. For these studies, we prepared $A \beta(16-22)$ that contained either ${ }^{13} \mathrm{C}$ or ${ }^{19} \mathrm{~F}$ labels to enable measurement of ${ }^{13} \mathrm{C}-{ }^{19} \mathrm{~F}$ distances by ssNMR dipolar recoupling experiments. We synthesized three peptides for these experiments. The first was an L-A $\beta(16-22)$ derivative with a $1-{ }^{13} \mathrm{C}$ label at Phe 19: L-Ac-KLVFFAE- $\mathrm{NH}_{2}$, with the $1-{ }^{13} \mathrm{C}$-labeled Phe underlined and in bold. Next, we synthesized L- and D-A $\beta(\overline{16}-22)$ enantiomers with 4-F-phenylalanine in the Phe 20 position (L-Ac-KLVF(4-F-Phe)AE- $\mathrm{NH}_{2}$ and D-Ac-klvf(4-F-phe)ae- $\mathrm{NH}_{2}$ ). For these peptides, a ${ }^{19} \mathrm{~F}$ label was chosen for correlative cross-coupling experiments due to the lack of commercial sources for D-amino acids with ${ }^{13} \mathrm{C}$ or ${ }^{15} \mathrm{~N}$ labels. The inclusion of a single $\mathrm{F}$ substituent on the Phe side chain is a conservative modification that does not significantly alter the assembly properties of the resulting $A \beta(16-22)$ variants (see Figure S4). These peptides were assembled in two combinations: L-Ac-KLVFFAE- $\mathrm{NH}_{2}$ with L-Ac-KLVF(4-F-Phe)AE- $\mathrm{NH}_{2}$ and L-Ac-KLVFFAE-NH ${ }_{2}$ with D-Ac-klvf(4-F-phe)ae- $\mathrm{NH}_{2}$. The first combination, L-Ac-KLVFFAE- $\mathrm{NH}_{2}$ with L-Ac-KLVF(4-F-Phe)AE- $\mathrm{NH}_{2}$ was expected to coassemble into pleated $\beta$-sheet fibrils in which the peptides are statistically mixed, creating three possible pairs: ${ }^{13} \mathrm{C}$ adjacent to ${ }^{13} \mathrm{C},{ }^{13} \mathrm{C}$ next to ${ }^{19} \mathrm{~F}$, and ${ }^{19} \mathrm{~F}$ adjacent to ${ }^{19} \mathrm{~F}$. When these peptides are aligned with a ${ }^{13} \mathrm{C}$ strand next to a ${ }^{19} \mathrm{~F}$ strand within the fibrils, the ${ }^{13} \mathrm{C}$ and ${ }^{19} \mathrm{~F}$ labels would be $8.63 \AA$ apart according to our putative model for these assemblies (Figure 5A, bottom of panel). The second combination, L-Ac-KLVFFAE- $\mathrm{NH}_{2}$ with D-Ac-klvf(4-F-phe)ae- $\mathrm{NH}_{2}$, was predicted to coassemble into rippled $\beta$-sheets with the $\mathrm{L}^{-}$and $\mathrm{D}$ - peptides precisely aligned in an alternating pattern so that the ${ }^{13} \mathrm{C}$ and ${ }^{19} \mathrm{~F}$ labels would be $6.48 \AA$ apart based on our predictive model (Figure 5B bottom of panel). 


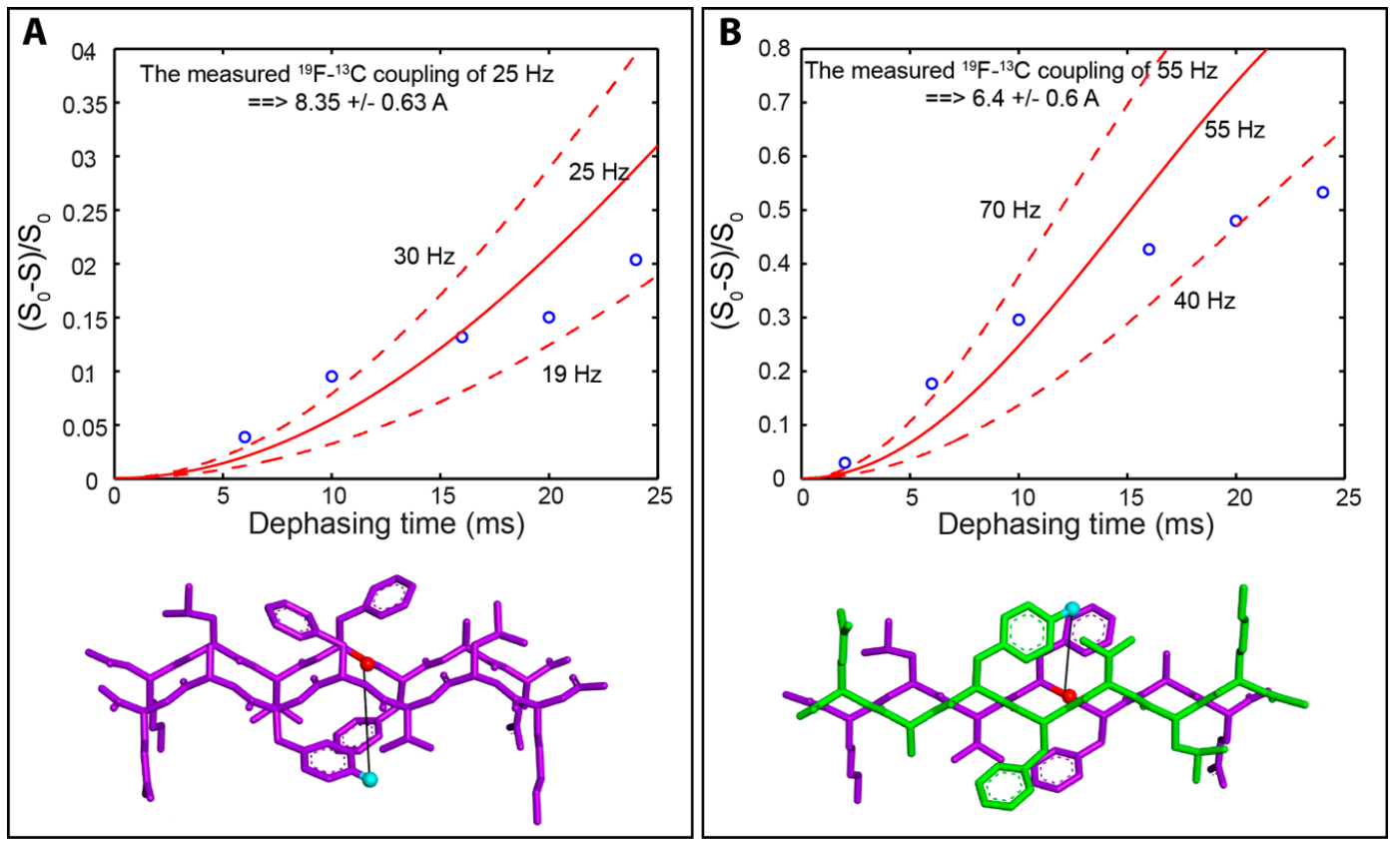

Figure 5. Dephasing curves for measurement of ${ }^{19} \mathrm{~F}-{ }^{13} \mathrm{C}$ distance correlations: ((A). Dephasing curve depicted as $\Delta \mathrm{S} / \mathrm{S}_{0}$ vs. dephasing time $(\mathrm{ms})$ used to determine the $1-{ }^{13} \mathrm{C}$ to ${ }^{19} \mathrm{~F}$ distance in pleated $\beta$-sheet cofibrils of L-Ac-KLVFFAE- $\mathrm{NH}_{2}$ with L-Ac-KLVF(4-F-Phe)AE- $\mathrm{NH}_{2}$. At the bottom of the panel is a predictive model for the cross-strand $\beta$-sheet orientation of these peptides with the $1-{ }^{13} \mathrm{C}$ label shown in red and the ${ }^{19} \mathrm{~F}$ label shown in cyan. The predicted ${ }^{19} \mathrm{~F}-{ }^{13} \mathrm{C}$ distance is $8.63 \AA$ and the measured ${ }^{19} \mathrm{~F}-{ }^{13} \mathrm{C}$ distance is $8.4 \AA$. (B) Dephasing curve depicted as $\Delta \mathrm{S} / \mathrm{S}_{0}$ vs. dephasing time (ms) used to determine the $1-{ }^{13} \mathrm{C}$ to ${ }^{19} \mathrm{~F}$ distance in rippled $\beta$-sheet cofibrils of $\mathrm{L}$-Ac-KLVFFAE- $\mathrm{NH}_{2}$ with D-Ac-klvf(4-F-phe)ae- $\mathrm{NH}_{2}$. At the bottom of the panel is a predictive model for the cross-strand $\beta$-sheet orientation of these peptides in rippled $\beta$-sheets with the $1-{ }^{13} \mathrm{C}$ label shown in red and the ${ }^{19} \mathrm{~F}$ label shown in cyan. The predicted ${ }^{19} \mathrm{~F}-13 \mathrm{C}$ distance is $6.48 \AA$ and the measured ${ }^{19} \mathrm{~F}-{ }^{13} \mathrm{C}$ distance is $6.4 \AA$.

The mixtures described above were coassembled to form cofibrils containing both ${ }^{13} \mathrm{C}$ and ${ }^{19} \mathrm{~F}$ in cross-strand positions within the pleated or rippled $\beta$-sheet assemblies. The L-Ac-KLVFFAE-NH ${ }_{2}$ with L-Ac-KLVF(4-F-Phe)AE- $\mathrm{NH}_{2}$ mixture assembled into pleated $\beta$-sheet fibers that were indistinguishable from those shown in Figure 3A,B as shown in Figure S4. Likewise, the L-Ac-KLVFFAE- $\mathrm{NH}_{2}$ with D-Ac-klvf(4-F-phe)ae- $\mathrm{NH}_{2}$ mixture coassembled to form more rigid rippled $\beta$-sheet assemblies that were identical to those depicted in Figure 3C,D (Figure S4).

These pleated and rippled $\beta$-sheet fibrils were then subjected to ssNMR analysis to measure cross-strand ${ }^{13} \mathrm{C}-{ }^{19} \mathrm{~F}$ distances in order to determine the accuracy of our models for the strand packing in pleated and rippled $\beta$-sheet assemblies. The labeled ${ }^{13} \mathrm{C}$ and ${ }^{19} \mathrm{~F}$ peaks are readily observed by ssNMR in both the pleated and rippled $\beta$-sheet assemblies, facilitating the use of cross-polarization magic angle spinning (CP/MAS) techniques [33-39] to enhance the labeled ${ }^{13} \mathrm{C}$ signal from protons and then to monitor the decay in the ${ }^{13} \mathrm{C}$ signal intensity due to ${ }^{19} \mathrm{~F}$ dephasing (Figure $5 \mathrm{~A}, \mathrm{~B}$ ) through rotational echo double resonance (REDOR) spectroscopy [40]. Detailed protocols are provided in the Materials and Methods section. Since we observed the ${ }^{13} \mathrm{C}$ signals (Figure S5, Supplemental Materials), two possible pairs $\left({ }^{13} \mathrm{C}\right.$ next to ${ }^{13} \mathrm{C}$ and ${ }^{13} \mathrm{C}$ next to $\left.{ }^{19} \mathrm{~F}\right)$ contribute to the observed $\mathrm{C} 13$ signals. For the pleated $\beta$-sheet fibrils of L-Ac-KLVFFAE- $\mathrm{NH}_{2}$ with L-Ac-KLVF(4-F-Phe)AE- $\mathrm{NH}_{2}$, the dephasing data is shown in Figure 5A where the dashed lines represent the strongest and weakest possible ${ }^{19} \mathrm{~F}^{13} \mathrm{C}$ dipolar couplings and the solid line was calculated using the ${ }^{19} \mathrm{~F}-{ }^{13} \mathrm{C}$ dipolar coupling in between. The obtained distances and the error bars were obtained based on the strongest and weakest ${ }^{19} \mathrm{~F}-{ }^{13} \mathrm{C}$ dipolar couplings. The data in Figure 5A indicates a dipolar coupling of $25 \mathrm{~Hz}$, which corresponds to a ${ }^{13} \mathrm{C}-{ }^{19} \mathrm{~F}$ distance of $8.4 \pm 0.6 \AA$, consistent with the predicted distance of $8.63 \AA$. Note, the statistical 
assembly was taken into account in this experiment. As seen in Figure S5, there are two ${ }^{13} \mathrm{C}$ peaks that reflect the two possible environments that this carbon can exist in based on the uncontrolled statistical assembly of the labeled peptides. Each REDOR point was obtained in two consecutive experiments, one without $\left(\mathrm{S}_{0}\right)$ and one with $(\mathrm{S})$ irradiation on the ${ }^{19} \mathrm{~F}$ channel. For the ${ }^{13} \mathrm{C}-{ }^{13} \mathrm{C}$ pair, there is no difference between the signal with and without the ${ }^{19} \mathrm{~F}$ irradiation. Thus, the ${ }^{13} \mathrm{C}-{ }^{13} \mathrm{C}$ signal is considered to be a background signal that does not contribute to the dipolar dephasing. Additionally, the ${ }^{19} \mathrm{~F}-{ }^{19} \mathrm{~F}$ pair does not affect the REDOR curves because we observed the ${ }^{13} \mathrm{C}$ signals.

For the rippled $\beta$-sheet assemblies of L-Ac-KLVFFAE-NH ${ }_{2}$ with D-Ac-klvf(4-F-phe)ae- $\mathrm{NH}_{2}$, the dephasing data (Figure 5B) gave a dipolar coupling of $55 \mathrm{~Hz}$, consistent with a ${ }^{13} \mathrm{C}-{ }^{19} \mathrm{~F}$ distance of $6.4 \pm 0.6 \AA$, very close to the predicted distance of $6.48 \AA$. Additionally, unlike the data obtained from the $\mathrm{L} / \mathrm{L}$ - fibrils, the raw SsNMR data obtained from the $\mathrm{L} / \mathrm{D}$ - sample was very sharp with no shoulders as shown in Figure S5, indicating a single packing pattern of ${ }^{13} \mathrm{C}$ next to ${ }^{19} \mathrm{~F}$, and confirming the formation of rippled $\beta$-sheets with strictly alternating $\mathrm{L} / \mathrm{D}$ packing structure in enantiomeric mixtures of $\mathrm{L}^{-}$and $\mathrm{D}-\mathrm{A} \beta(16-22)$ as opposed to statistical mixtures as in the L-Ac-KLVFFAE- $\mathrm{NH}_{2} \mathrm{with}$ L-Ac-KLVF(4-F-Phe)AE-NH ${ }_{2}$. These data are also consistent with the predictive models for pleated and rippled $\beta$-sheets that indicate an "eclipsed"-like arrangement of side chain cross-strand packing in pleated $\beta$-sheets and a "staggered"-like arrangement of side chains in rippled $\beta$-sheets. These differences in packing structure most likely account for the relative energetic stability of rippled $\beta$-sheets.

\section{Conclusions}

In conclusion, previous reports have shown that enantiomeric amphipathic peptides with alternating hydrophilic and hydrophobic side chains readily coassemble into rippled $\beta$-sheets, as predicted by Pauling and Corey [13,17-20]. Here, we have demonstrated that this phenomenon is not restricted to $\beta$-strand peptides with this particular sequence pattern but can be extended to the peptide $A \beta(16-22)$, which has a nonpolar core and polar termini. The results reported herein also indicate that rippled $\beta$-sheet formation via coassembly of enantiomeric peptides is kinetically and thermodynamically favorable relative to the self-assembly of the corresponding individual enantiomers. The basis for these preferences is not yet completely understood, but is likely due to the altered cross-strand packing structure in rippled $\beta$-sheets compared to pleated $\beta$-sheets, which has been recently shown to adopt a "staggered" side chain conformations (rippled sheets), as opposed to "eclipsed" side chain conformations (pleated sheets) [19]. The extension of rippled $\beta$-sheet formation suggested by the study reported herein is also consistent with recent work that showed that neurotoxic species were avoided when full-length $\mathrm{L}-\mathrm{A} \beta_{42}$ and $\mathrm{D}-\mathrm{A} \beta_{42}$ were mixed, resulting in unique aggregates suggestive of rippled $\beta$-sheets [29]. Also, cross-seeding of poly-glutamine amyloid by seeds of the opposite enantiomer suggest that rippled $\beta$-sheets are also accessible by this amyloid species [41]. However, there are some examples of enantiomeric mixtures of self-assembling peptides that do not successfully coassemble, and instead self-sort. Recent work has shown that disulfide bound dimers of peptides derived from $\beta 2$-microglobulin self-sort and that enantiomeric mixtures of full length $\beta 2$-microglobulin mostly self-sort, with perhaps a small amount of coassembly occurring [42]. From this study, it is apparent that the ability of enantiomeric $\beta$-sheet peptides to undergo coassembly is not straightforward, and thus invites further study. More detailed high-resolution structural analyses of rippled $\beta$-sheet materials, including the $A \beta(16-22)$ materials described herein, will provide additional insight into the preference for enantiomeric rippled $\beta$-sheet assembly and will facilitate the design of novel rippled $\beta$-sheet materials and strategies whereby these mechanisms might be exploited to divert amyloid assembly in vivo into non-destructive pathways. 


\section{Materials and Methods}

\subsection{Peptide Synthesis}

All peptides were synthesized using standard solid-phase techniques with Fmoc protection and HBTU/HOBt or DIC/HOBt activation on Rink amide resin (Advanced ChemTech, 100-200 mesh, 0.27 $\mathrm{mmol} / \mathrm{g}$, Louisville, KY, USA) as $\mathrm{N}$-acetyl, $\mathrm{C}$-terminal amide sequences. After Fmoc deprotection of the final amino acid, the $N$-termini were acetylated followed by sidechain deprotection and cleavage from the resin using a 95:2.5:2.5 v/v trifluoroacetic acid:triisopropylsilane:water solution. The resulting solution was concentrated and cold diethyl ether was added to initiate precipitation of the crude peptide product. The precipitate was pelleted out via centrifugation and dissolved in DMSO prior to purification by preparatory HPLC.

\subsection{Peptide Purification and Characterization}

Peptide purification was performed using a reverse phase Phenomenex Gemini (5 $\mu \mathrm{m}, \mathrm{NX}-\mathrm{C} 18$, $110 \AA$, $250 \times 21.2 \mathrm{~mm}$, Phenomenex, Torrance, CA, USA) column on a Shimadzu LC 6-AD HPLC (Shimadzu Corporation, Nakagyo-ku, Kyoto, Japan) with a binary gradient of water and acetonitrile with $0.1 \%$ TFA at $10 \mathrm{~mL} \mathrm{~min}^{-1}$. UV absorbance at 215 and $254 \mathrm{~nm}$ of the eluent was monitored for fraction collection. Peptide purity was confirmed using MALDI-TOF mass spectroscopy and analytical HPLC using a reverse phase Phenomenex Gemini $(5 \mu \mathrm{m}, \mathrm{C} 18,110 \AA$, $250 \times 4.6 \mathrm{~mm}$, Phenomenex, Torrance, CA, USA) column on a Shimadzu LC-2010A (Shimadzu Corporation, Nakagyo-ku, Kyoto, Japan). Following purification, purified peptide fractions were lyophilized prior to disaggregation and assembly.

\subsection{Peptide Disaggregation Protocol}

Peptide disaggregation was performed using a modified Wetzel protocol [28]. Lyophilized, purified peptide samples were dissolved in $2 \mathrm{~mL}$ TFA and sonicated for $10 \mathrm{~min}$. After sonication, TFA was evaporated under a gentle stream of nitrogen and the resulting peptide film reconstituted in $2 \mathrm{~mL}$ HFIP and incubated at $37^{\circ} \mathrm{C}$ for $90 \mathrm{~min}$. Following incubation, the HFIP was evaporated under a gentle stream of nitrogen and the resulting peptide film again taken up in $2 \mathrm{~mL}$ HFIP. Peptide concentration was then checked by diluting $10 \mu \mathrm{L}$ peptide solution in DMSO and analyzing via analytical HPLC for comparison to a concentration curve calibrated by amino acid analysis. Peptide solution was then aliquoted appropriately into lo-bind Eppendorf tubes and dried in vacuo for $16 \mathrm{~h}$.

\subsection{Sedimentation Assays}

Sedimentation assays were performed using a modified Wetzel protocol [28]. Dried, disaggregated peptide aliquots were dissolved in DMSO and diluted into the desired amount of phosphate buffered saline (137 mM NaCl, $2.7 \mathrm{mM} \mathrm{KCl}, 10 \mathrm{mM} \mathrm{Na}_{2} \mathrm{HPO}_{4}, 1.8 \mathrm{mM} \mathrm{KH}_{2} \mathrm{PO}_{4}, \mathrm{pH} 7.4,0.1 \% \mathrm{NaN}_{3} w / v$; DMSO was $5 \%$ by volume of the final solution) in glass vials. For coassembly samples, $\mathrm{L}^{-}$and $\mathrm{D}$ - peptides were kept separate until dilution into PBS. Samples were incubated at $37^{\circ} \mathrm{C}$ and $250 \mu \mathrm{L}$ aliquots were removed at predetermined times. Aliquots were then centrifuged at $436,000 \times g$ for $1 \mathrm{~h}$ at $4{ }^{\circ} \mathrm{C}$ to remove oligomeric and fibrillar aggregates. After centrifugation, the supernatant was collected and diluted with DMSO to halt further assembly. These solutions were then analyzed by analytical HPLC for correlation to a concentration curve to determine remaining monomer concentration.

\subsection{Solid-State Fourier Transform Infrared Spectroscopy (FTIR)}

Dried, disaggregated peptide aliquots were prepared for assembly as in sedimentation assays, but in larger volumes (greater than or equal to $5 \mathrm{~mL}$ ) and were allowed to assemble for 21 days so as to allow for complete assembly of all samples. Following assembly, samples were centrifuged at $4300 \times g$ for $90 \mathrm{~min}$ at $17^{\circ} \mathrm{C}$ to collect aggregates. The supernatant was then carefully removed and deionized 
water added, mixed, and centrifugation repeated to wash. After first wash, supernatant was again removed and deionized water added and mixed, at which point samples were spotted for TEM or SEM if desired (below). Centrifugation was repeated once more and supernatant removed, and then samples were frozen and lyophilized. Lyophilized pellets were then placed on the solid-state stage of a Shimadzu FTIR-8400S (Shimadzu Corporation, Nakagyo-ku, Kyoto, Japan) spectrometer and analyzed at a resolution of $4 \mathrm{~cm}^{-1}$.

\subsection{Transmission Electron Microscopy (TEM)}

Fibrils for the TEM images reported were obtained from the same samples that were used for FTIR, above, at the same timepoint. Fibrils were washed as described above and $5 \mu \mathrm{L}$ aliquots of the resulting fibril solutions in water were applied to TEM grids (carbon film coated copper, 200 mesh; Electron Microscopy Sciences, Hatfield, PA, USA) and allowed to adsorb for $30 \mathrm{~s}$. The excess fluid was removed by capillary action and then $5 \mu \mathrm{L} \mathrm{5 \%}$ uranyl acetate was allowed to adsorb on the grid for 2 min to stain the sample. Excess staining solution was removed by capillary action and grids were allowed to dry in air for $10 \mathrm{~min}$. TEM images were recorded on a Hitachi 7650 transmission electron microscope in high contrast mode with an accelerating voltage of $80 \mathrm{kV}$. Fibril widths were measured in Image J and are reported as averages from 100-150 measurements.

\subsection{Scanning Electron Microscopy (SEM)}

Fibrils were washed as described above and $5 \mu \mathrm{L}$ aliquots of the resulting fibril solutions in water were applied to round $12 \mathrm{~mm}$ coverglasses and allowed to dry. Coverglasses were then mounted onto aluminum stubs, sputter coated with gold, and imaged using a Zeiss Auriga Field Emission Scanning Electron Microscope (Zeiss International, Oberkochen, Germany).

\subsection{Solid State Nuclear Magnetic Resonance (ssNMR) Spectroscopy}

Dried, disaggregated peptide aliquots were prepared for assembly as in sedimentation assays, but in large volumes $(90 \mathrm{~mL})$ at high concentrations of total peptide $(0.78 \mathrm{mM})$ and were allowed to assemble for 8 days prior to collection and washing as described in FTIR sample prep. Lyophilized materials were analyzed at the National High Magnetic Field Lab (Tallahassee, Florida, USA).

Solid state NMR experiments were performed on a Bruker Avance $600 \mathrm{MHz}$ NMR spectrometer (Bruker Corporation, Billerica, MA, USA) with a Bruker HFX triple-resonance MAS NMR probe (Bruker Corporation, Billerica, MA, USA) and equipped with a Bruker pneumatic MAS unit (Bruker Corporation, Billerica, MA, USA). Samples were spun at $13 \mathrm{kHz} \pm 3 \mathrm{~Hz}$. The Larmor frequencies of ${ }^{1} \mathrm{H}$, ${ }^{19} \mathrm{~F}$, and ${ }^{13} \mathrm{C}$ are $600.13,564.64$, and $150.91 \mathrm{MHz}$, respectively. ${ }^{13} \mathrm{C}$ magnetization was enhanced from ${ }^{1} \mathrm{H}$ through cross polarization using a contact time of $1.5 \mathrm{~ms}$, during which a ${ }^{1} \mathrm{H}$ spin-lock field of 50 $\mathrm{kHz}$ was used and the ${ }^{13} \mathrm{C} \mathrm{B}_{1}$ field was ramped from 45 to $65 \mathrm{kHz}$. The rotor synchronized spin-echo pulse sequence was used to record ${ }^{13} \mathrm{C}$ signals. $\mathrm{A}^{13} \mathrm{C} 180^{\circ}$ pulse was applied on the chemical shift position of $\sim 175 \mathrm{ppm}$ in the middle of the spin-echo time. Two ${ }^{19} \mathrm{~F} 180^{\circ}$ pulses per rotor period were applied during the spin-echo time (or dephasing time) in order to dephase the ${ }^{13} \mathrm{C}$ magnetization due to the recovery of the ${ }^{13} \mathrm{C}-{ }^{19} \mathrm{~F}$ dipolar coupling. The ${ }^{19} \mathrm{~F} 180^{\circ}$ pulse length was $6.0 \mu$ s. The XY-8 pulse sequence [43] was applied to the ${ }^{19} \mathrm{~F} 180^{\circ}$ pulse trains in order to compensate for the flip angle error and the off-resonance effects. A SPINAL64 decoupling sequence [44] with a ${ }^{1} \mathrm{H} \mathrm{B}_{1}$ field of $62.5 \mathrm{kHz}$ was used during the spin-echo time and acquisition. A MATLAB program was used to calculate the dephasing curves at various distances. The ${ }^{13} \mathrm{C}$ chemical shift was referenced to the carbonyl carbon resonance of glycine at $178.4 \mathrm{ppm}$ relative to TMS.

Supplementary Materials: The following are available online. Table S1: HPLC gradient conditions, Figure S1: analytical HPLC traces, Table S2: Calculated and observed $m / z$ values (MALDI-TOF-MS), Figure S2: MALDI-TOF-MS spectra, Figure S3: Peptide concentration curves, Figure S4: Additional TEM images, Figure S5: ssNMR one-dimensional ${ }^{13} \mathrm{C}$ spectra. 
Author Contributions: Conceptualization, B.L.N.; peptide synthesis and characterization, J.M.U., J.H., and G.P.; sedimentation analysis, TEM imaging, and ssNMR prep, J.M.U.; SEM sample prep and FTIR, J.H.; performing ssNMR experiments and data analysis, R.F.; writing-original draft preparation, J.M.U.; writing-review and editing, B.L.N.; funding acquisition, B.L.N.

Funding: This research was funded by the National Science Foundation, grant number DMR-1148836 and the National Heart, Lung, and Blood Institute of the National Institutes of Health, grant number R01HL138538. J.M.U. was partially supported by a Robert L. and Mary L. Sproull University Fellowship from the University of Rochester. The NMR experiments were carried out at the National High Magnetic Field Lab (NHMFL) supported by the NSF cooperative agreement N. DMR-1644779 and the State of Florida.

Acknowledgments: We thank Karen Bentley at the URMC Electron Microscopy Research Core for assistance with SEM imaging and for TEM training. We also thank Danielle Raymond for designing molecular models for our TOC image, Figure 4B,C, and the bottom panels of Figure 5.

Conflicts of Interest: The authors declare no conflict of interest.

\section{References}

1. Ow, S.Y.; Dunstan, D.E. A brief overview of amyloids and Alzheimer's disease. Protein Sci. 2014, 23, 1315-1331. [CrossRef] [PubMed]

2. Hamley, I.W. Peptide fibrillization. Angew. Chem. Int. Ed. Engl. 2007, 46, 8128-8147. [CrossRef] [PubMed]

3. Harrison, R.S.; Sharpe, P.C.; Singh, Y.; Fairlie, D.P. Amyloid peptides and proteins in review. Rev. Physiol. Biochem. Pharmacol. 2007, 159, 1-77. [CrossRef] [PubMed]

4. Eisenberg, D; Jucker, M. The amyloid state of proteins in human diseases. Cell 2012, 148, 1188-1203. [CrossRef] [PubMed]

5. Chiti, F.; Dobson, C.M. Protein misfolding, functional amyloid, and human disease. Annu. Rev. Biochem 2006, 75, 333-366. [CrossRef]

6. Wang, M.; Audas, T.E.; Lee, S. Disentangling a Bad Reputation: Changing Perceptions of Amyloids. Trends Cell Biol. 2017, 27, 465-467. [CrossRef] [PubMed]

7. Antonets, K.S.; Nizhnikov, A.A. Amyloids and prions in plants: Facts and perspectives. Prion 2017, 11, 300-312. [CrossRef]

8. Maji, S.K.; Perrin, M.H.; Sawaya, M.R.; Jessberger, S.; Vadodaria, K.; Rissman, R.A.; Singru, P.S.; Nilsson, K.P.; Simon, R.; Schubert, D.; et al. Functional amyloids as natural storage of peptide hormones in pituitary secretory granules. Science 2009, 325, 328-332. [CrossRef]

9. Som Chaudhury, S.; Das Mukhopadhyay, C. Functional amyloids: Interrelationship with other amyloids and therapeutic assessment to treat neurodegenerative diseases. Int. J. Neurosci. 2017, 128, 1-15. [CrossRef]

10. Eskandari, S.; Guerin, T.; Toth, I.; Stephenson, R.J. Recent advances in self-assembled peptides: Implications for targeted drug delivery and vaccine engineering. Adv. Drug Deliv. Rev. 2017, 110-111, 169-187. [CrossRef]

11. Waku, T.; Tanaka, N. Recent advances in nanofibrous assemblies based on $\beta$-sheet-forming peptides for biomedical applications. Polym. Int. 2017, 66, 277-288. [CrossRef]

12. King, P.J.; Giovanna Lizio, M.; Booth, A.; Collins, R.F.; Gough, J.E.; Miller, A.F.; Webb, S.J. A modular self-assembly approach to functionalised beta-sheet peptide hydrogel biomaterials. Soft Matter 2016, 12, 1915-1923. [CrossRef] [PubMed]

13. Pauling, L.; Corey, R.B. Two Rippled-Sheet Configurations of Polypeptide Chains, and a Note about the Pleated Sheets. Proc. Natl. Acad. Sci. USA 1953, 39. [CrossRef] [PubMed]

14. Fuhrhop, J.-H.; Krull, M.; Büldt, G. Precipitates with $\beta$-Pleated Sheet Structure by Mixing Aqueous Solutions of Helical Poly(D-lysine) and Poly(L-lysine). Angew. Chem. Int. Ed. 1987, 26, 699-700. [CrossRef]

15. Dzwolak, W.; Ravindra, R.; Nicolini, C.; Jansen, R.; Winter, R. The diastereomeric assembly of polylysine is the low-volume pathway for preferential formation of beta-sheet aggregates. J. Am. Chem. Soc. 2004, 126, 3762-3768. [CrossRef]

16. Yamaoki, Y.; Imamura, H.; Fulara, A.; Wojcik, S.; Bozycki, L.; Kato, M.; Keiderling, T.A.; Dzwolak, W. An FT-IR study on packing defects in mixed beta-aggregates of poly(L-glutamic acid) and poly(D-glutamic acid): A high-pressure rescue from a kinetic trap. J. Phys. Chem. B 2012, 116, 5172-5178. [CrossRef]

17. Swanekamp, R.J.; Welch, J.J.; Nilsson, B.L. Proteolytic stability of amphipathic peptide hydrogels composed of self-assembled pleated beta-sheet or coassembled rippled beta-sheet fibrils. Chem. Commun. 2014, 50, 10133-10136. [CrossRef] 
18. Swanekamp, R.J.; DiMaio, J.T.; Bowerman, C.J.; Nilsson, B.L. Coassembly of enantiomeric amphipathic peptides into amyloid-inspired rippled beta-sheet fibrils. J. Am. Chem. Soc. 2012, 134, 5556-5559. [CrossRef]

19. Nagy-Smith, K.; Beltramo, P.J.; Moore, E.; Tycko, R.; Furst, E.M.; Schneider, J.P. Molecular, Local, and Network-Level Basis for the Enhanced Stiffness of Hydrogel Networks Formed from Coassembled Racemic Peptides: Predictions from Pauling and Corey. ACS Cent. Sci. 2017, 3, 586-597. [CrossRef]

20. Nagy, K.J.; Giano, M.C.; Jin, A.; Pochan, D.J.; Schneider, J.P. Enhanced mechanical rigidity of hydrogels formed from enantiomeric peptide assemblies. J. Am. Chem. Soc. 2011, 133, 14975-14977. [CrossRef]

21. Balbach, J.J.; Ishii, Y.; Antzutkin, O.N.; Leapman, R.D.; Rizzo, N.W.; Dyda, F.; Reed, J.; Tycko, R. Amyloid Fibril Formation by A $\beta 16-22$, a Seven-Residue Fragment of the Alzheimer's $\beta$-Amyloid Peptide, and Structural Characterization by Solid State NMR. Biochemistry 2000, 39, 13748-13759. [CrossRef] [PubMed]

22. Senguen, F.T.; Doran, T.M.; Anderson, E.A.; Nilsson, B.L. Clarifying the influence of core amino acid hydrophobicity, secondary structure propensity, and molecular volume on amyloid-beta 16-22 self-assembly. Mol. Biosyst. 2011, 7, 497-510. [CrossRef]

23. Senguen, F.T.; Lee, N.R.; Gu, X.; Ryan, D.M.; Doran, T.M.; Anderson, E.A.; Nilsson, B.L. Probing aromatic, hydrophobic, and steric effects on the self-assembly of an amyloid-beta fragment peptide. Mol. Biosyst. 2011, 7, 486-496. [CrossRef]

24. Wood, S.J.; Wetzel, R.; Martin, J.D.; Hurle, M.R. Prolines and amyloidogenicity in fragments of the Alzheimer's peptide beta/A4. Biochemistry 1995, 34, 724-730. [CrossRef] [PubMed]

25. Hilbich, C.; Kisters-Woike, B.; Reed, J.; Masters, C.L.; Beyreuther, K. Substitutions of hydrophobic amino acids reduce the amyloidogenicity of Alzheimer's disease $\beta A 4$ peptides. J. Mol. Biol. 1992, 228, 460-473. [CrossRef]

26. Inouye, H.; Gleason, K.A.; Zhang, D.; Decatur, S.M.; Kirschner, D.A. Differential effects of Phe19 and Phe20 on fibril formation by amyloidogenic peptide A beta 16-22 (Ac-KLVFFAE-NH $_{2}$. Proteins 2010, 78, 2306-2321. [CrossRef]

27. Klimov, D.K.; Thirumalai, D. Dissecting the Assembly of A $\beta 16-22$ Amyloid Peptides into Antiparallel $\beta$ Sheets. Structure 2003, 11, 295-307. [CrossRef]

28. O’Nuallain, B.; Thakur, A.K.; Williams, A.D.; Bhattacharyya, A.M.; Chen, S.; Thiagarajan, G.; Wetzel, R. Kinetics and Thermodynamics of Amyloid Assembly Using a High-Performance Liquid Chromatography-Based Sedimentation Assay. Methods Enzymol. 2006, 413, 34-74. [CrossRef] [PubMed]

29. Dutta, S.; Foley, A.R.; Warner, C.J.A.; Zhang, X.; Rolandi, M.; Abrams, B.; Raskatov, J.A. Suppression of Oligomer Formation and Formation of Non-Toxic Fibrils upon Addition of Mirror-Image Abeta42 to the Natural l-Enantiomer. Angew. Chem. Int. Ed. Engl. 2017, 56, 11506-11510. [CrossRef] [PubMed]

30. Childers, W.S.; Mehta, A.K.; Lu, K.; Lynn, D.G. Templating molecular arrays in amyloid's cross-beta grooves. J. Am. Chem. Soc. 2009, 131, 10165-10172. [CrossRef] [PubMed]

31. Krysmann, M.J.; Castelletto, V.; Kelarakis, A.; Hamley, I.W.; Hule, R.A.; Pochan, D.J. Self-assembly and hydrogelation of an amyloid peptide fragment. Biochemistry 2008, 47, 4597-4605. [CrossRef]

32. Tjernberg, L.O.; Callaway, D.J.E.; Tjernberg, A.; Hahne, S.; Lilliehöök, C.; Terenius, L.; Thyberg, J.; Nordstedt, C. A Molecular Model of Alzheimer Amyloid $\beta$-Peptide Fibril Formation. J. Biol. Chem. 1999, 274, 12619-12625. [CrossRef]

33. Stejskal, E.O.; Schaefer, J.; Waugh, J.S. Magic-angle spinning and polarization transfer in proton-enhanced NMR. J. Magn. Reson. 1977, 28, 105-112. [CrossRef]

34. Kotecha, M.; Wickramasinghe, N.P.; Ishii, Y. Efficient low-power heteronuclear decoupling in ${ }^{13} \mathrm{C}$ high-resolution solid-state NMR under fast magic angle spinning. Magn. Reson. Chem. 2007, 45 (Suppl. 1), S221-S230. [CrossRef]

35. Wickramasinghe, N.P.; Ishii, Y. Sensitivity enhancement, assignment, and distance measurement in ${ }^{13} \mathrm{C}$ solid-state NMR spectroscopy for paramagnetic systems under fast magic angle spinning. J. Magn. Reson. 2006, 181, 233-243. [CrossRef]

36. Yannoni, C.S. High-resolution NMR in solids: The CPMAS experiment. Acc. Chem. Res. 2002, 15, $201-208$. [CrossRef]

37. Goldbourt, A. Biomolecular magic-angle spinning solid-state NMR: Recent methods and applications. Curr. Opin. Biotechnol. 2013, 24, 705-715. [CrossRef] [PubMed]

38. Pines, A.; Gibby, M.G.; Waugh, J.S. Proton-enhanced NMR of dilute spins in solids. J. Chem. Phys. 1973, 59, 569-590. [CrossRef] 
39. Schaefer, J.; Stejskal, E.O. Carbon-13 nuclear magnetic resonance of polymers spinning at the magic angle. J. Am. Chem. Soc. 1976, 98, 1031-1032. [CrossRef]

40. Gullion, T.; Schaefer, J. Rotational-echo double-resonance NMR. J. Magn. Reson. 1989, 81, 196-200. [CrossRef]

41. Kar, K.; Arduini, I.; Drombosky, K.W.; van der Wel, P.C.; Wetzel, R. D-polyglutamine amyloid recruits L-polyglutamine monomers and kills cells. J. Mol. Biol. 2014, 426, 816-829. [CrossRef] [PubMed]

42. Torbeev, V.; Grogg, M.; Ruiz, J.; Boehringer, R.; Schirer, A.; Hellwig, P.; Jeschke, G.; Hilvert, D. Chiral recognition in amyloid fiber growth. J. Pept. Sci. 2016, 22, 290-304. [CrossRef]

43. Gullion, T.; Baker, D.B.; Conradi, M.S. New, compensated Carr-Purcell sequences. J. Magn. Reson. 1990, 89, 479-484. [CrossRef]

44. Fung, B.M.; Khitrin, A.K.; Ermolaev, K. An improved broadband decoupling sequence for liquid crystals and solids. J. Magn. Reson. 2000, 142, 97-101. [CrossRef] [PubMed]

Sample Availability: Samples of the compounds are not available from the authors.

(C) 2019 by the authors. Licensee MDPI, Basel, Switzerland. This article is an open access article distributed under the terms and conditions of the Creative Commons Attribution (CC BY) license (http://creativecommons.org/licenses/by/4.0/). 